\title{
Recency and primacy in causal judgments: Effects of probe question and context switch on latent inhibition and extinction
}

\author{
STEVen GLautier \\ University of Southampton, Southampton, England
}

\begin{abstract}
Traditional associative models assume that associative weights are updated on a trial-by-trial basis. As a result, it is usually expected that responses based on these weights will tend to reflect the most recently presented contingencies. However, a number of studies of human causal judgments have shown primacy effects, wherein judgments obtained at the end of a series of trials are more strongly influenced by a contingency that was in force early in the sequence than by a contingency that was in force later in the sequence. The experiments described in this article replicated other work showing that requesting causal judgments during a sequence can reverse primacy and produce strong recency effects. Evidence was also obtained to suggest that primacy effects are produced by an interaction between latent inhibition and extinction processes and that requesting a judgment affects both of these processes.
\end{abstract}

Associative theories (e.g., the Rescorla-Wagner model) suggest that causal judgments are based on the strength of an associative link between a mental representation of the cause and a mental representation of the effect (Rescorla \& Wagner, 1972). This associative link is updated on a trial-by-trial basis, so judgments should tend to reflect the most recently experienced contingency. As a result, if participants experience a positive followed by a negative contingency between a putative cause and an effect, they should judge a cue as less of a cause than if they have experienced a negative followed by a positive contingency between the cause and the effect.

However, exactly the opposite result has been found in a number of experiments. Instead of finding recency effects, some investigators have found primacy effects. For example, Dennis and Ahn (2001) carried out a study in which they presented participants with a series of trials. On each trial, the participants were given information on whether consumption of an exotic plant produced a physical reaction. After the trial series, the participants then had to judge the extent to which the plant was a cause of the reaction. Over the entire trial series, the overall contingency between consumption and reaction was zero, as measured using $\Delta p$ (Allan, 1980). Experimental conditions were created such that, within the context of this zero contingency, the participants experienced confirmatory trials predominantly in the first half of the series (a CF series) or predominantly in the second half of the series (a CS series). Confirmatory trials were defined as Cells A and $\mathrm{D}$ from the standard $2 \times 2$ contingency table, whereas disconfirmatory trials were defined as Cells B and C.
Cell A and Cell D trials are those on which the putative cause is present along with the effect and those on which both the cause and the effect are absent, respectively. Cell B and Cell C trials are those on which the cause is present and the effect is absent and those on which the cause is absent and the effect is present, respectively. It might be expected under these two conditions that judgments would be equivalent, as suggested by $\Delta p$, or that there would be a recency effect, reflecting a trial-by-trial updating process with higher ratings given following a CS series. In fact, a primacy effect was observed. Higher ratings were given following a $\mathrm{CF}$ series.

Using a similar design, Collins and Shanks (2002) found either that the order of confirmatory and disconfirmatory information made no difference (Experiments 3 and 4) or that a primacy effect was observed (Experiment 2). In addition, Collins and Shanks found recency effects, so that a contingency was judged as more causal following a CS series. This recency effect was found when causal judgments were made more frequently (after every block of 10 trials) than when they were made once, at the end of the trial series. Other investigators have also reported an effect of judgment frequency (Catena, Maldonado, \& Cándido, 1998; Catena, Maldonado, Megías, \& Frese, 2002; Matute, Vegas, \& De Marez, 2002), and Catena et al. (1998; Catena et al., 2002) proposed a beliefupdating model (cf. also Hogarth \& Einhorn, 1992) for the effects of judgment frequency on causal judgments.

In this belief-updating model, judgments are based on a weighted sum of new information accumulated since the previous judgment and the previous judgment, rather than

S. Glautier, spg@soton.ac.uk 
on associative strengths that are updated on a trial-by-trial basis, as in the Rescorla-Wagner Model. In an initial test of this model, Catena et al. (1998) found that participants gave higher causal ratings in a symptom-disease task when judgments were made immediately after experiencing confirmatory Cell A and Cell D trials than after disconfirmatory Cell B and Cell C trials. However, this effect was present only when the participants made judgments on every trial. For these participants, some confirmatory trials would have been immediately preceded by disconfirmatory trials, and judgments would have been increased by the causal value of the new information. On the other hand, the participants who made judgments after every block of trials would not have been subject to this effect. For these participants, new information accumulated between judgments was identical whatever trial type (confirmatory or disconfirmatory) immediately preceded the judgments. Although the model proposed by Catena et al. (1998; Catena et al., 2002) offers an account of increased sensitivity to recent information when frequent judgments are requested, the observation of primacy effects is more problematic (e.g., Collins \& Shanks, 2002; Curley, Young, Kingrey, \& Yates, 1988; Dennis \& Ahn, 2001).

The present article examines whether or not both primacy and recency effects in causal judgments can be understood from the perspective of an acquisition-focused (Miller \& Escobar, 2001) approach to learning. Specifically, it might be possible to understand primacy, as well as recency, effects in the context of a trial-by-trial associative model if the rate of associative change could decline over the course of a trial series and if requesting judgments during the series could restore the rate of associative change. In such a situation, the rating of a cue exposed to a CF series would be high when tested only once, at the end of the series, because extinction in the second half of the trials would be slow. In contrast, in the case of a CS series, the cue would receive a low rating, because acquisition in the second half of the series would be slow. This pattern represents a primacy effect. On the other hand, instead of judgments being requested only at the end of the trial series, if judgments were requested more frequently, the rate of associative change would not decline, and judgments would mirror the most recent contingency. Thus, judgments following a CS series would be high, whereas judgments following a CF series would be low.

\section{EXPERIMENT 1}

A three-pronged approach is required to establish whether the effect of judgment frequency on primacy and recency can be understood in terms of an effect on the rate of acquisition and extinction. First, the paradigm in use must produce a clear effect of judgment frequency on primacy and recency. Second, evidence for the involvement of acquisition is required. It should be shown that acquisition slows down later in the trial series and that requesting a judgment restores acquisition. Third, evidence for the involvement of extinction effects must be obtained. Judgments should decline in the second half of a CF trial sequence, and this rate of decline should be greater under conditions of more frequent judgments. Evidence on each of these points was obtained in the present experiment, using a causal judgment task in which participants viewed a series of trials. Each trial gave information on whether or not consumption of a particular food produced illness. All the participants were exposed to four foods; two were presented in a CF series, and two were presented in a CS series. At the end of the trial series, all the participants judged the extent to which each of the foods produced illness. In one group (PJ), this final judgment was made after a previous judgment made in the middle of the trial series. In the other group (NJ), no judgment was requested mid-series.

\section{Method}

Participants. Fifty participants were recruited from the campus of Southampton University and from the School of Psychology at University College London. Posted advertisements requested volunteers for an investigation of causal learning and offered payment of $£ 4$ or course credit for taking part. Twenty-five participants were tested in each of two groups. Age and gender data were lost for 2 participants. For the remaining 48, the average age was 21.7 years, and the group contained 20 males.

Apparatus and Stimuli. During the experiment, the participants operated IBM-compatible PCs with either 15-in. $(43.2-\mathrm{cm})$ or 17 -in. (38.1-cm) color monitors running in an 800 (width) $\times 600$ (height) pixel resolution. Stimuli serving as cues were 26 images of various fruit and vegetables (e.g., tomato, apple, avocado) depicted in $100 \times$ 100 pixel, 8-bit color bitmaps that occupied squares with 3-cm (approximate) sides that were presented in the top half of the screen, centered horizontally. Presentation of the cue was accompanied by a 1-sec auditory alerting bleep. Outcome information and instructions during the rating phases were presented in the lower part of the screen.

Design and Procedure. On arrival, the participants were given a brief verbal description of the procedure before reading and signing a consent form. Before starting the experiment, the participants were given a more detailed verbal description of the procedure. This information was presented once again, on-screen, and the participants were asked to read the following description before starting:

In this experiment your job is to learn the extent to which each of various foods produce sickness. You play the role of a doctor investigating recent reports of food poisoning. The food poisoning is believed to be linked to fruit and vegetables purchased at a local market and in order to track the source of the poisoning you have interviewed people who have recently eaten various fruit and vegetables purchased from the market. You are reviewing the information you have collected on a case by case basis. For each case you have information on which foods were eaten and whether or not the person was well or sick after eating. Your job is to learn the extent to which each of the foods might be a cause of sickness. Note, the sequence of trials is randomly ordered so you can only predict sickness by learning about the food items themselves. At various points you will be asked to indicate what your judgements are. When you have to make a judgement this will be signalled on the screen. All you have to do is follow the onscreen instructions and enter a number that reflects your judgement. Instructions will be given on how to make your rating, please take care to read all of the instructions carefully. Once you have made your judgment press return to carry on. Press a key to continue.

All the participants were then exposed to two blocks of 48 trials, with the order of trials within each block randomized for each participant. Within each block, all the participants were exposed to 12 trials involving each of four foods: A, B, C, and D. The particular foods serving these stimulus roles were selected randomly for each participant from the pool of 26 items. The contingencies in force for 
Table 1

Designs Used in Experiments 1-3

\begin{tabular}{|c|c|c|c|c|}
\hline Group & Block 1 & Test & Block 2 & Test \\
\hline \multicolumn{5}{|l|}{ Experiment 1} \\
\hline Group PJ & $\mathrm{A}+, \mathrm{B}+, \mathrm{C}-, \mathrm{D}-$ & $\mathrm{A} ?, \mathrm{~B} ?, \mathrm{C} ?, \mathrm{D} ?$ & $\mathrm{~A}-, \mathrm{B}-, \mathrm{C}+, \mathrm{D}+$ & $\mathrm{A} ?, \mathrm{~B} ?, \mathrm{C} ?, \mathrm{D} ?$ \\
\hline Group NJ & $\mathrm{A}+, \mathrm{B}+, \mathrm{C}-, \mathrm{D}-$ & & $\mathrm{A}-, \mathrm{B}-, \mathrm{C}+, \mathrm{D}+$ & $\mathrm{A} ?, \mathrm{~B} ?, \mathrm{C} ?, \mathrm{D} ?$ \\
\hline \multicolumn{5}{|l|}{ Experiment 2} \\
\hline All & $\mathrm{A}+, \mathrm{B}+, \mathrm{C}-, \mathrm{D}-$ & $\mathrm{A} ?, \mathrm{AC} ?, \mathrm{BN} ?$ & & \\
\hline \multicolumn{5}{|l|}{ Experiment 3} \\
\hline Group NJ & $\mathrm{A}+, \mathrm{B}+, \mathrm{C}-, \mathrm{D}-$ & & $\mathrm{A}-, \mathrm{B}-, \mathrm{C}+, \mathrm{D}+$ & $\mathrm{A} ?, \mathrm{~B} ?, \mathrm{C} ?, \mathrm{D} ?$ \\
\hline Group NJ-CTX & $\mathrm{A}+, \mathrm{B}+, \mathrm{C}-, \mathrm{D}-$ & & $\mathbf{A}-, \mathbf{B}-, \mathbf{C}+, \mathbf{D}+$ & A?, B?, C?, D? \\
\hline
\end{tabular}

Note-Plus signs indicate that a food was paired with illness on 9 out of 12 trials. Minus signs indicate that food was paired with illness on 3 out of 12 trials. A question mark indicates a test trial in which the participants were asked to provide a rating for the indicated items. In Experiment 3, the boldface type indicates a new context. Blanks indicate that no scheduled events took place. See the text for more details.

each food changed at the end of the first block. For Foods A and B, confirmatory trials were presented predominantly in the first block, whereas disconfirmatory trials were presented predominantly in the second block. Thus, Foods A and B were presented in a CF series. This pattern was reversed for Foods $\mathrm{C}$ and $\mathrm{D}$; they were presented in a CS series. Over the two blocks, all the foods had the same contingent relationship with sickness. Table 1 summarizes the design. Procedurally, each trial started with a 3-sec presentation of a food. The screen was then cleared, and outcome information was shown for $2 \mathrm{sec}$. The outcome information consisted of the words, "After eating this food the person was:" followed by either "well" or "sick" according to the design. The screen was then cleared for a $1-\mathrm{sec}$ interval before the next trial began.

The participants were tested in one of two groups, PJ and NJ. All the participants judged the extent to which each food caused illness at the end of the trial series. For PJ participants, the end-ofseries judgment had been preceded by previous judgments of each food at the end of Block 1. For NJ participants, no judgment was made at the end of Block 1. The transition between blocks was unsignaled for Group NJ, and for Group PJ only the request for judgments signaled the transition; there was no indication that contingencies might change during the series. Judgments were made by presenting the foods, one by one, and asking for a judgment for each one. The test items were presented in a random order generated for each participant, and each item was accompanied by the following instructions:

To what extent do you think this food is a cause of sickness? Use a scale of 0 to 100.0 means "not a cause." 100 means "very strong cause." Use any number 0-100 to make your rating.

The food remained on display until the judgment was made, and the next test trial followed after a delay of $1 \mathrm{sec}$.

\section{Results}

Figure 1 shows the averaged ratings for the $\mathrm{CF}$ (A and $\mathrm{B}$ ) and $\mathrm{CS}(\mathrm{C}$ and $\mathrm{D})$ foods that were obtained for each of the groups on tests carried out at the end of the series. These end-of-series ratings (four columns on the right-hand side) show that recency effects were obtained for Group PJ (CF < $\mathrm{CS}$ ), whereas primacy effects were found for Group NJ $(\mathrm{CF}>\mathrm{CS})$. This suggests that judgment frequency affected recency and primacy, and the pattern was confirmed by an ANOVA with cue (CF vs. CS) and group (PJ vs. NJ) as factors. This analysis showed a significant cue $\times$ group interaction but no main effects $[F(1,48)=23.0, p<.001$; $\left.F_{\mathrm{S}}(1,48)<1\right]$. Follow-up $t$ tests showed a significant primacy effect $(\mathrm{CF}>\mathrm{CS})$ in Group NJ $[t(24)=4.2, p<.001]$ and a significant recency effect $(\mathrm{CF}<\mathrm{CS})$ in Group PJ $[t(24)=2.8, p<.05]$.
The ratings for Group PJ obtained after the first block are shown in the first two columns of Figure 1. Analyses incorporating these data allow assessment of acquisition and extinction processes in the recency and primacy effects already described. The involvement of acquisition effects is shown in a comparison of the Stage $1 \mathrm{CF}$ ratings obtained from Group PJ and the final ratings of the CS cues obtained from Group NJ. The Stage 1 CF ratings in Group PJ were higher than the final ratings for CS cues in Group NJ $[t(48)=6.4, p<.001]$. Since the Block 2 trials for Group NJ were identical to the Block 1 trials for Group PJ, this indicates that acquisition in Block 2 was less effective for Group NJ in Block 2 than for Group PJ in Block 1. Considering the final ratings, the CS cues in Group PJ were rated higher than the CS cues in Group NJ $[t(48)=3.0, p<.01]$. This suggests that acquisition in Block 2 was more effective for Group PJ

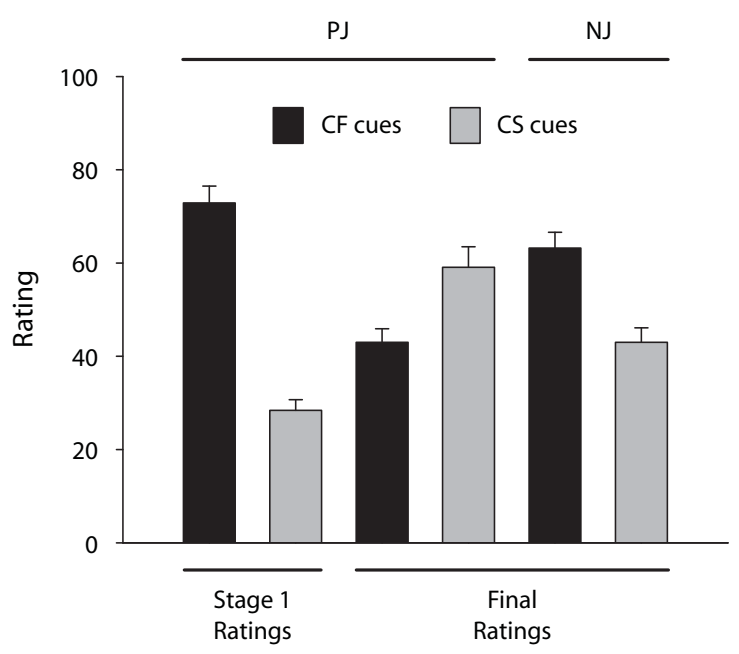

Figure 1. Initial and final ratings for the two groups in Experiment 1 (means plus standard errors). The previous judgment group (PJ) rated cues at the end of Stage 1; these ratings are shown in the first two columns on the left-hand side. Both groups made final ratings; these are shown in the four columns on the right-hand side. NJ, no-judgment group; CF, confirmatory trials predominantly in first half of series; CS, confirmatory trials predominantly in second half of series. 
than for Group NJ; that is, the midpoint judgment restored acquisition.

Turning to extinction, evidence of an extinction effect can be seen in the comparison of the Stage 1 and final ratings for Group PJ. Final ratings of the CF cues were lower than Stage 1 ratings $[t(24)=6.5, p<.001]$. The fact that final ratings for the $\mathrm{CF}$ cues were lower for Group PJ than for Group NJ $[t(48)=4.5, p<.001]$ suggests that extinction was more rapid for Group PJ than for Group NJ; that is, the midpoint judgment increased the extinction rate.

\section{EXPERIMENT 2}

In Experiment 1, three points of evidence supported the view that the effects of judgment frequency on primacy and recency could be interpreted in terms of effects on rate of acquisition and extinction: (1) Primacy effects were found in the $\mathrm{NJ}$ condition, and recency effects were found in the PJ condition; (2) acquisition was shown to be more rapid in the early part of the trial series, and requesting a judgment restored the rate of acquisition; and (3) extinction effects were observed and the rate of extinction was increased after a judgment was made.

The present experiment was carried out to investigate further the acquisition effects observed in Experiment 1. Lubow (e.g., 1973) is associated with the phenomena of latent inhibition. Latent inhibition refers to a reduction in the rate of acquisition that occurs as a result of nonreinforced exposure to a stimulus. Experiment 1 can be said to have demonstrated retardation of acquisition, since the Stage 1 rating of the CF cue in Group PJ was higher than the final rating of the CS cue in Group NJ. This could have been a product of latent inhibition's arising from the nonreinforced trials in Block 1. However, it is conventional to distinguish latent inhibition effects from conditioned inhibition effects by the application of both retardation and summation tests (Rescorla, 1971). Since the RescorlaWagner model can anticipate acquisition of inhibitory strength by the CS cues ${ }^{1}$ during Block 1 and since the Block $1 \Delta p$ value for the CS cues was $-1 / 3$, it is important to rule out a contribution of conditioned inhibition, rather than latent inhibition, to the observed retardation effect. This was carried out by repeating the Block 1 procedure and then carrying out a summation test on the CS cues.

\section{Method}

Differences from Experiment 1 are noted below.

Participants. Twenty participants were tested. They were recruited from the campus of Southampton University; their average age was 20.5 years, and 3 of them were male.

Design and Procedure. All the participants in this experiment were exposed to the same Block 1 trials as those used in Experiment 1 and were then asked to make ratings of the CF Cues A and B, which had a $\Delta p$ value of $1 / 3$ when presented alone, when presented in compound with CS Cues $\mathrm{C}$ and $\mathrm{D}$, which had a $\Delta p$ value of $-1 / 3$, and when presented in compound with novel cues $(\mathrm{CF}-\mathrm{N})$, which had not been encountered before. If the $\mathrm{CF}-\mathrm{CS}$ compound was rated lower than $\mathrm{CF}$, this might indicate a conditioned inhibition effect. However, the CF-CS compound was a novel stimulus; it was the first time a compound had been encountered, and this might produce generalization decrement. Generalization decrement was assessed in ratings of the $\mathrm{CF}-\mathrm{N}$ compound. Evidence for conditioned inhibition would be

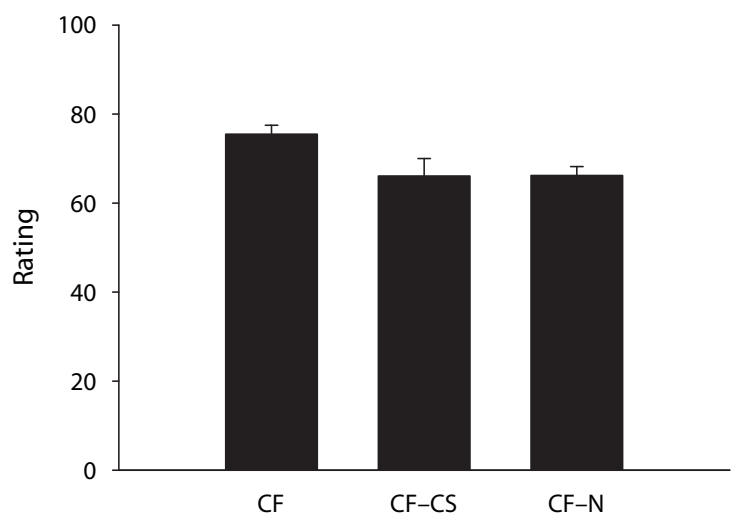

Figure 2. Ratings for the three cues (CF, $\mathrm{CF}-\mathrm{CS}, \mathrm{CF}-\mathrm{N})$ in $\mathbf{E x}-$ periment 2 (means plus standard errors). CF, confirmatory trials predominantly in first half of series; CS, confirmatory trials predominantly in second half of series; $\mathrm{N}$, novel.

obtained if $\mathrm{CF}-\mathrm{CS}$ was rated lower than $\mathrm{CF}$ and lower than $\mathrm{CF}-\mathrm{N}$ (Escobar, Arcediano, \& Miller, 2003). Table 1 illustrates the design.

\section{Results}

Figure 2 shows the ratings of $\mathrm{CF}, \mathrm{CF}-\mathrm{CS}$, and $\mathrm{CF}-\mathrm{N}$. It can be seen that $\mathrm{CF}$ received a higher rating when presented alone than when presented in compound with the CS, which is suggestive of conditioned inhibition. However, a similar reduction in rating was produced by adding a novel stimulus; therefore, this reduction could be explained equally well as a generalization decrement. A oneway ANOVA showed that there were significant overall differences between these means $[F(1.4,27.5)=4.6, p<$ .05 , Greenhouse-Geisser corrected $d f \mathrm{~s}$ ] . Pairwise $t$ tests showed significant differences between $\mathrm{CF}$ and $\mathrm{CF}-\mathrm{CS}$ and between $\mathrm{CF}$ and $\mathrm{CF}-\mathrm{N}[t \mathrm{~s}(19)>2.3, p \mathrm{~s}<.05]$ but no difference between CF-CS and CF-N $[t(19)=0.02]$.

\section{EXPERIMENT 3}

Experiment 2 provided evidence that the retardation of acquisition seen for the $\mathrm{CS}$ cues in Block 2 of the $\mathrm{NJ}$ condition in Experiment 1 was not due to the acquisition of inhibitory strength during Block 1 . At the end of Block 1 , CS cues did not pass a summation test for inhibition. Failing a summation test for inhibition in combination with retarded acquisition is a signature of latent inhibition (Rescorla, 1971). In the present experiment, further evidence was sought on the possible role of latent inhibition in the $\mathrm{NJ}$ condition. Latent inhibition has often been reported to be context dependent, so that a change of context between preexposure and conditioning phases prevents retardation (e.g., Channell \& Hall, 1983; Rosas \& Bouton, 1997). It is possible that it was the probe question that was effective in producing an increase in acquisition during Block 2 for the CS cues, due to the creation of a context shift by the probe question. If so, a similar effect should be seen using an alternative contextual manipulation. Escobar et al. (2003) used contextual manipulations consisting of a change in background screen color, presentation of ad- 
ditional instructions, and a temporal break between phases (Experiment 3 ) in a study of human latent inhibition. In the present experiment, all three of these components were used between Blocks 1 and 2 in order to produce a context shift.

\section{Method}

Differences from Experiment 1 are described below.

Participants. Thirty-five participants were tested. They were recruited from the campus of Southampton University. Nineteen were tested in Group NJ, and 16 were tested in an NJ-context-switch group (NJ-CTX). Their average age was 19.7 years, and 7 of them were male.

Design and Procedure. The design is summarized in Table 1. Groups NJ and NJ-CTX were exposed to the same contingencies as those used in Experiment 1. Group NJ received the same treatment as Group NJ in Experiment 1, but for Group NJ-CTX there was a context switch between Blocks 1 and 2. Participant instructions were altered to accommodate this switch by inserting, between the sentence ending "food items themselves" and the sentence beginning "At various points," the following sentence: "In the first part of the experiment you will see cases where food was bought from market A and in the second part you will see cases where food was bought from market B." The actual context switch, then, consisted of a 15 -sec pause between blocks, during which the following text was displayed: "The first part of the experiment is over. You will now see foods from a different market. Please wait for the second part to begin." After the 15 -sec pause, the text disappeared, and the screen background color changed from white to gray and remained gray for the rest of the experiment. Block 2 began immediately after the pause.

\section{Results}

Figure 3 shows the end-of-series ratings for $\mathrm{CF}$ ( $\mathrm{A}$ and $\mathrm{B}$ ) and CS (C and D) cues obtained after Block 2 in Group NJ, which had no context switch between blocks, and in Group NJ-CTX, which had a context switch between blocks. It can be seen that primacy effects were present in both groups $(\mathrm{CF}>\mathrm{CS})$. However, this primacy effect was smaller in Group NJ-CTX. A cue $(\mathrm{CF}$ vs. CS) $\times$ group (NJ vs. NJ-CTX) ANOVA produced the following results. There was no main effect of group $[F(1,33)=1.6]$, but

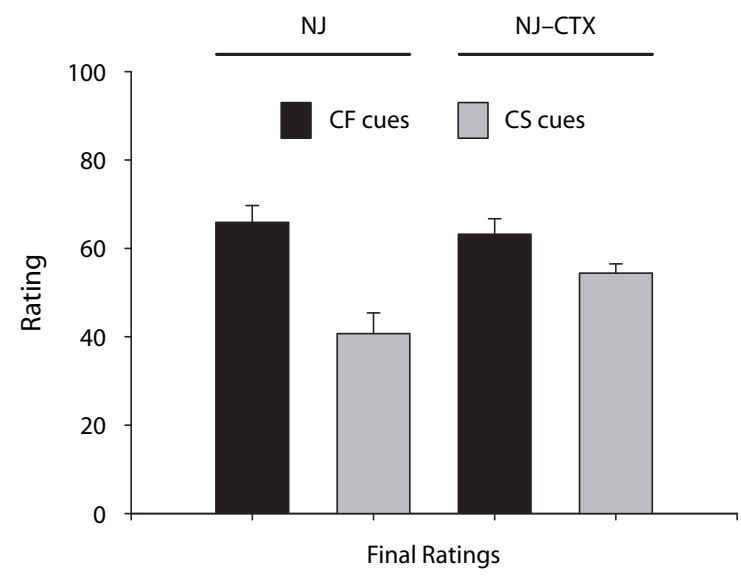

Figure 3. Final ratings for the two groups (NJ and NJ-CIX) in Experiment 3 (means plus standard errors). NJ, no-judgment group; NJ-CTX, NJ-context-switch group. there was a main effect of cue $[F(1,33)=28.3, p<.001]$ and a cue $\times$ group interaction $[F(1,33)=6.6, p<.05]$. The interaction indicated that the primacy effect was reliably smaller in Group NJ-CTX than in Group NJ. Followup $t$ tests showed a significant primacy effect in both cases $[t(15)=2.3, p<.05$, for NJ-CTX, and $t(18)=5.2, p<$ .001 , for NJ]. The reduction in the size of the primacy effect in Group NJ-CTX was brought about by a reduction in the size of the latent inhibition effect, rather than an increase in the rate of extinction. The CS cue acquired more strength in Group NJ-CTX than in Group NJ $[t(33)=$ $2.5, p<.05]$, but the CF cues were equivalent in the two groups $[t(33)=0.53]$.

\section{DISCUSSION}

Experiment 1 demonstrated primacy effects in association with retarded acquisition and extinction during Block 2 of the trial series. Recency effects were observed if a probe question was introduced halfway through the trial series. Recency was brought about by an apparent increase in acquisition and extinction during Block 2. It was suggested that the nonreinforced trials in the CS contingency of Block 1 might have produced a latent inhibition effect that would account for reduced acquisition in Block 2. In Experiment 2, a summation test was used to show that the retarding effect of the Block 1 contingency was not due to development of conditioned inhibition. If the probe question at the halfway stage is regarded as producing a context shift, the change from primacy to recency can be understood as an effect of context on latent inhibition and extinction. Both are well known to be context dependent. Latent inhibition can be abolished by context shifts (e.g., Channell \& Hall, 1983; Escobar et al., 2003), and extinction occurs more rapidly after context change (e.g., Hall \& Honey, 1989; Mackintosh, 1974). Experiment 3 used a different contextual manipulation, similar to one that has previously been shown to disrupt latent inhibition in humans (Escobar et al., 2003). Primacy effects were disrupted but not abolished by this manipulation. This disruption occurred as the result of an effect on latent inhibition; acquisition occurred more quickly in Block 2 after the context shift. There was no apparent effect of the context switch on extinction in Block 2 .

Although the interactions among context, primacy, and recency effects appeared to involve latent inhibition and extinction processes in these experiments, the question of how context mediates these effects remains to be resolved. A number of accounts, none of which seems entirely adequate, will be considered below.

The introduction highlighted the difficulties faced by the acquisition-focused models of Rescorla and Wagner (1972) and Catena et al. (1998; Catena at al., 2002). Whereas the Rescorla-Wagner model predicts constant recency effects, the belief-updating model anticipates an effect of judgment frequency on the strength of recency effects but does not predict primacy. One alternative acquisition-focused model offers an explanation of learning based on changes in the associability of stimuli, so that the rate of learning declines as stimuli become good 
predictors of their outcomes (Hall, 1991; Pearce \& Hall, 1980). In this model, latent inhibition might be predicted during Stage 1 as a result of a decline in the associability of $\mathrm{CS}$ cues as they become predictors of nonreinforcement. As a consequence, when Stage 2 reinforcement begins, initial learning will be reduced while the associability of the cue is restored. Thus, this model might account for the latent inhibition effect seen in the present experiments. In addition, slow extinction might be explained, since the $\mathrm{CF}$ cues in Stage 1 will also have their associability reduced, and the impact of the initial extinction trials will, therefore, be reduced while associability is restored.

However, the partial reinforcement schedules used in these experiments ensures that Pearce-Hall associability remains high enough during simulations, so that with equal numbers of Stage 1 and Stage 2 trials, the model cannot predict primacy effects at the end of Stage 2. ${ }^{2}$ It may be possible to supplement this model by assuming that there can be a global reduction in associability in an experimental setting in which boredom and/or fatigue may affect participants. This effect will be at a maximum in the NJ conditions, so that strong latent inhibition and weak extinction may conspire to produce primacy effect. If context shifts produce a global restoration of associability, this can result in a reduction in latent inhibition and more rapid extinction to produce the recency effects seen in these conditions. But this model cannot account for the apparent dissociation of latent inhibition and extinction effects seen in Experiment 3.

As an alternative to acquisition-focused models, there are performance-focused alternatives (Miller \& Escobar, 2001). In this type of model, it is assumed that all information from different learning episodes is retained (e.g., extinction is not unlearning) and that differences in behavior reflect the operation of mechanisms that select among the possible meanings that are attached to stimuli. The two-stage discrimination reversal design used in the present experiments is a prime example in which stimuli are trained with multiple meanings and what is learned in the first and second stages for each cue conflicts. It has been argued that context is used to resolve such conflicts and that the ambiguous meaning of the cue, that which is learned in the second phase, becomes contextually dependent (Bouton, 1997; Nelson, 2002).

There are many examples in which behavior after ambiguous learning experiences has been shown to be dependent on the context in which the different components of training and testing have been carried out (see Pineño \& Miller, 2005, for a recent review). For example, Thomas, Larsen, and Ayres (2003) found that a change of context following acquisition and extinction resulted in renewed responding, consistent with the initial acquisition phase, rather than with the extinction phase. In other words, this was an $\mathrm{AAB}$ design, in which the letters $\mathrm{A}$ and $\mathrm{B}$ signified the context in which each experimental phase was carried out, which showed a renewal effect. By analogy, the primacy effect seen in the NJ conditions in the present experiments may have been mediated, in part, by renewal of responding to the $\mathrm{CF}$ cues if the context set by the final probe question itself is taken into account; that is, the NJ condition could be cast as an AAB design. Similarly, latent inhibition effects have been shown to be dependent on context. In the PJ group (Experiment 1) and the NJ-CTX group (Experiment 3), the context switches at the halfway stage may have contributed to the reduced latent inhibition seen in these groups and, hence, to the recency (Experiment 1 ) or reduced primacy (Experiment 3 ) effects seen in these groups.

Although this type of analysis for the effect of probe question is appealing, further research will be required to establish its validity. A number of problems complicate the simple picture outlined above. For example, if administration of the probe questions does set a new context, marking another phase of the experiment, the structure of the trials in the PJ groups in Experiment 1 could be characterized as $\mathrm{ABC}$, with Phase $\mathrm{C}$ being the final test. However, more renewal following extinction can be produced in $\mathrm{ABC}$ designs than in $\mathrm{AAB}$ designs (Thomas et al., 2003). The fact that renewal (primacy) was more marked in the NJ groups (AAB design by analogy) stands against this interpretation.

Others have developed performance-focused accounts suggesting that participants are flexible in their utilization of information and that their strategy can be influenced by the nature of the probe questions (Collins \& Shanks, 2002; Matute et al., 2002). The probe questions were constant across conditions in these experiments, so this cannot be the factor differentiating the PJ, NJ, and $\mathrm{NJ}-\mathrm{CTX}$ conditions. However, it is possible that the context shifts (produced by probe questions or by a change of instructional set) implicitly produced a strategy of giving weight to later information (Vadillo, Vegas, \& Matute, 2004). Similarly, the end-of-series questions may have implicitly encouraged integration, although, as with Catena et al.'s (1998; Catena et al., 2002) model, it is not clear why such strong primacy should emerge. Vadillo et al. did observe an enhanced primacy type effect when contextual manipulations specifically cued participants to early information, but there was no reason to suppose that this type of effect would occur in this study. Indeed, assuming that the NJ design resembles the $\mathrm{AAB}$ contexts, the present $\mathrm{NJ}$ design maps onto Vadillo et al.'s parallel finding of integrative responding (Vadillo et al., 2004, Experiment 2/3, Group Global-112).

In conclusion, although it is not possible to offer a complete explanation for the observed interactions between context, primacy, and recency effects, it is clearly necessary to consider a model based on contextual effects on latent inhibition and extinction processes. Introduction of a probe question in the middle of the trial series appears to be a particularly effective form of context shift. It seems possible that other studies have reported primacy effects (e.g., Dennis \& Ahn, 2001) when the context change between different experimental stages was less marked than in studies showing recency effects.

A further clear factor appears to be the nature of the question asked of the participants. Hogarth and Einhorn's (1992) review identified a majority of studies that produced primacy effects, and in many of these studies, participants' judgments referenced what might be expected 
to be stable attributes-for example, trait descriptors. More recent work has emphasized the distinction between causal and predictive judgments (Collins \& Shanks, 2002; Matute et al., 2002), with causal judgments more likely to produce integrative judgments or primacy effects. Perhaps the key factor that will shift a judgment about relatively stable properties of the world, such as cause-effect relations, from recency to integration to primacy (Pineño $\&$ Miller, 2005) is the degree of context change that is evident between stages. Since latent inhibition and extinction are differentially sensitive to context manipulations (Experiment 3), a complex pattern across studies is to be expected. Why should latent inhibition and extinction be differentially sensitive to context effects? It can be suggested that weak beliefs are easier to modify than strong ones; this is analogous to Bouton's (1993) suggestion that inhibitory associations are more context dependent than excitatory associations.

\section{AUTHOR NOTE}

Data from these experiments were presented at the 8th Associative Learning Symposium at Gregynog Hall, University of Wales, 2004 (Experiment 1) and at the XIX Spanish Society of Comparative Psychology Conference in Madrid, 2007 (Experiments 1-3). Acknowledgments to Anthony Dickinson for his suggestion that primacy effects can be produced by a trial-by-trial model under conditions of strong latent inhibition effects and weak extinction; to David Shanks, who facilitated use of UCL laboratories for testing participants during a period of sabbatical leave (Experiment 1); to Byron Nelson, for his detailed comments on a draft; and to an anonymous reviewer for suggesting that the asymmetry of context effects in Experiment 3 could have been due to differences between weak and strong beliefs. Correspondence concerning this article should be addressed to S. Glautier, School of Psychology, University of Southampton, Southampton SO17 1BJ, England (e-mail: spg@soton.ac.uk).

\section{REFERENCES}

Allan, L. G. (1980). A note on the measurement of contingency between two binary variables. Bulletin of the Psychonomic Society, 15 147-149.

Bouton, M. E. (1993). Context, time, and memory retrieval in the interference paradigms of Pavlovian learning. Psychological Bulletin, 114, 80-99.

Bouton, M. E. (1997). Signals for whether versus when an event will occur. In M. E. Bouton \& M. S. Fanselow (Eds.), Learning, motivation, and cognition: The functional behaviorism of Robert C. Bolles (pp. 385-409). Washington, DC: American Psychological Association.

Catena, A., Maldonado, A., \& Cándido, A. (1998). The effect of the frequency of judgment and the type of trials on covariation learning. Journal of Experimental Psychology: Human Perception \& Performance, 24, 481-495.

Catena, A., Maldonado, A., Megías, J. L., \& Frese, B. (2002). Judgement frequency, belief revision, and serial processing of causal information. Quarterly Journal of Experimental Psychology, 55B, 267-281.

Channell, S., \& Hall, G. (1983). Contextual effects in latent inhibition with an appetitive conditioning procedure. Animal Learning \& Behavior, 11, 67-74.

Collins, D. J., \& Shanks, D. R. (2002). Momentary and integrative response strategies in causal judgment. Memory \& Cognition, 30, 1138-1147.

Curley, S. P., Young, M. J., Kingrey, M. J., \& Yates, F. (1988). Primacy effects in clinical judgements of contingency. Medical Decision Making, 8, 216-222.
Dennis, M. J., \& AhN, W.-K. (2001). Primacy in causal strength judgments: The effect of initial evidence for generative versus inhibitory relationships. Memory \& Cognition, 29, 152-164.

Escobar, M., Arcediano, F., \& Miller, R. R. (2003). Latent inhibition in human adults without masking. Journal of Experimental Psychology: Learning, Memory, \& Cognition, 29, 1028-1040.

HALL, G. (1991). Perceptual and associative learning. Oxford: Oxford University Press, Clarendon Press.

Hall, G., \& Honey, R. C. (1989). Contextual effects in conditioning, latent inhibition, and habituation: Associative and retrieval functions of contextual cues. Journal of Experimental Psychology: Animal Behavior Processes, 15, 232-241.

Hogarth, R. M., \& Einhorn, H. J. (1992). Order effects in beliefupdating: The belief-adjustment model. Cognitive Psychology, 24, $1-55$.

Lubow, R. E. (1973). Latent inhibition. Psychological Bulletin, 79, 398-407.

MaCKINTOSH, N. J. (1974). The psychology of animal learning. London: Academic Press.

Matute, H., Vegas, S., \& De Marez, P.-J. (2002). Flexible use of recent information in causal and predictive judgments. Journal of Experimental Psychology: Learning, Memory, \& Cognition, 28, 714725.

Miller, R. R., \& Escobar, M. (2001). Contrasting acquisition-focussed and performance-focussed models of acquired behavior. Current Directions in Psychological Science, 10, 141-145.

NeLson, J. B. (2002). Context specificity of excitation and inhibition in ambiguous stimuli. Learning \& Motivation, 33, 284-310.

Pearce, J. M., \& Hall, G. (1980). A model for Pavlovian learning: Variations in the effectiveness of conditioned but not unconditioned stimuli. Psychological Review, 87, 532-552.

Pineño, O., \& Miller, R. R. (2005). Primacy and recency effects in extinction and latent inhibition: A selective review with implications for models of learning. Behavioural Processes, 69, 223-235.

RESCORLA, R. A. (1971). Summation and retardation tests of latent inhibition. Journal of Comparative \& Physiological Psychology, 75, 77-81.

Rescorla, R. A., \& Wagner, A. R. (1972). A theory of Pavlovian conditioning: Variations in the effectiveness of reinforcement and non-reinforcement. In A. H. Black \& W. F. Prokasy (Eds.), Classical conditioning II: Current research and theory (pp. 64-69). New York: Appleton-Century-Crofts.

Rosas, J. M., \& Bouton, M. E. (1997). Additivity of the effects of retention interval and context change on latent inhibition: Toward resolution of the context forgetting paradox. Journal of Experimental Psychology: Animal Behavior Processes, 23, 283-294.

Thomas, B. L., Larsen, N., \& Ayres, J. J. B. (2003). Role of context similarity in $\mathrm{ABA}, \mathrm{ABC}$, and $\mathrm{AAB}$ renewal paradigms: Implications for theories of renewal and for treating human phobias. Learning \& Motivation, 34, 410-436.

Vadillo, M. A., Vegas, S., \& Matute, H. (2004). Frequency of judgment as a context-like determinant of predictive judgments. Memory \& Cognition, 32, 1065-1075.

\section{NOTES}

1. Simulations of the Rescorla-Wagner (1972) model for this design leave the CS cues with a small amount of excitatory strength after Stage 1, unless a cue is present on all trials to represent the context. If the CS cues are tested with this context, there is weak excitation. If the CS cues are tested without this context, there is weak inhibition.

2. In some cases, the model may be able to predict a primacy effect. Due to the randomized orders, there will be some long runs of reinforced and nonreinforced trials during Stage 1, so that associability is low when the contingency changes.

(Manuscript received October 25, 2005; revision accepted for publication April 20, 2008.) 